\title{
Pilot randomised controlled trial of the Risk Acceptance Ladder (RAL) as a tool for targeting health communications
}

Olga Perski ${ }^{1}$, Claire Stevens ${ }^{1}$, Robert West ${ }^{1}$, Lion Shahab ${ }^{1}$

1 University College London, University of London

\begin{abstract}
Objective: To assess the possible effectiveness of an online version of the Risk Acceptance Ladder (RAL) in promoting help-seeking relating to a range of health behaviours.
\end{abstract}

Design: Pilot randomised controlled trial.

Methods: 843 UK adults were recruited, of whom 602 eng aged in at least one of four risky health behaviours; cigarette smoking, excessive alcohol consumption, insufficient physical activity, or low fruit and veg etable consumption. Those with no immediate plans to change completed a behaviour specific RAL $(n=171)$. Participants were randomised to one of two conditions; a short message congruent (on-target, $n=73$ ) or incongruent (off-target, $n=98$ ) with their RAL response. Performance of the RAL was assessed by participants' ability to select an applicable RAL item and reported ease of use of the RAL. Effectiveness of the RAL was assessed by whether or not participants clicked a link to receive information about changing their target behaviour.

Results: Two thirds $(68.9 \%, 95 \% \mathrm{Cl}=61.8 \%-75.3 \%)$ of participants were able to select an applicable RAL item that corresponded to what they believed would need to change in order to change their target behaviour and $64.9 \%(95 \% \mathrm{Cl}=57.5 \%-71.7 \%)$ reported that it was easy to select one option. Participants allocated to the on-target group were more likely to click on the link to receive information (31.5\% vs $19.4 \%$; OR $=2.07$, $95 \% \mathrm{Cl}=1.01-4.26)$.

Conclusions: The Risk Acceptance Ladder may have utility as a tool for tailoring messages to prompt initial steps to eng aging in self-protective behaviours. 


\section{Introduction}

Improving adherence to self-protective behaviours, or reducing harmful behaviours, is an important goal for public health (Hay et al., 2017). This includes, but is not limited to, stopping tobacco use, reducing alcohol consumption, improving diet and increasing physical activity (Forouzanfar et al., 2016; NHS Digital, 2019; World Health Organisation, 2018). A commonly used framework for developing behaviour change interventions is the Behaviour Change Wheel (Michie, Atkins, \& West, 2014). A key process in this framework is identifying which aspects of someone's capability, opportunity and/or motivation need to change in order for the behaviour to change (Michie, van Stralen, \& West, 2011). This paper describes a preliminary evaluation of a self-report measure, the Risk Acceptance Ladder (RAL) (Cattaruzza \& West, 2013; Gould, Watt, McEwen, CadetJames, \& Clough, 2014; Gould, Watt, West, Cadet-James, \& Clough, 2016), that aims to establish what aspects of capability, opportunity and/or motivation to focus on in a behaviour change intervention to prompt someone to take an initial step in making the change.

There has been a large amount of research on tailoring behaviour change interventions to individual characteristics. A commonly used model, the transtheoretical model, has been used to tailor interventions according to a putative stage in the change process: 'precontemplation', 'contemplation', 'preparation', 'action', and 'maintenance' (Prochaska \& DiClemente, 1982, 1983). There is mixed evidence that stage-matched interventions can be more effective than mismatched ones (Blissmer \& McAuley, 2002; Quinlan \& McCaul, 2000) and there is also evidence that interventions that ig nore stage matching can be more effective than ones that seek to identify the stage of change and only offer support to people who show an interest (Romain et al., 2018; Van Sluijs, Van Poppel, \& Van Mechelen, 2004; West, 2005).

The Risk Acceptance Ladder (RAL) was developed with the idea that people might themselves have some level of insight into what would be required for them to change their behaviour (Cattaruzza \& West, 2013; Gould et al., 2014, 2016). Using the CapabilityOpportunity-Motivation-Behaviour (COM-B) model, it proposed that there might be a natural hierarchy of factors leading to the current risky behaviour. The person may never have heard that it was risky, may have heard about it but not understood the message, may have understood it but not believed it, may have believed it but not been concerned about it, may have been concerned but not enough to outweigh the perceived benefits of the risky behaviour, or may have been sufficiently concerned but found it difficult for a 
number of external or internal reasons. If it turns out that people have some insight into what is preventing change, and this can be classified hierarchically, a brief questionnaire may provide a useful starting point for targeting interventions to initiate change. This is an unknown and so it was important to undertake a preliminary evaluation.

This study aimed to evaluate an online version of the RAL focusing on four important health-related behaviours: smoking, alcohol consumption, diet and physical activity. In principle, the approach could be used for other health behaviours such as risky driving, infection control or sexual health behaviours. The choice of an online test of the tool was motivated by the fact that, if it was shown to have some value, it would be easy to implement through websites and online platforms, and also that it was possible to establish an easily measurable behavioural response in terms of 'clicking through' to a page that would represent a first stage in the change process.

The research questions addressed by the current study were:

1. To assess performance: How readily can respondents choose a single 'rung' of the Risk Acceptance Ladder as a possible target for change?

2. To assess effectiveness: Does messaging that directly addresses the selected 'rung' (on-target messaging) lead to a higher likelihood of taking an initial step in making the change than messaging that addresses a different 'rung' (off-target messaging)?

\section{Methods}

\section{Study design and setting}

This was a pilot, parallel group randomised controlled trial (RCT) conducted in the UK. The Paper Authoring Tool (https://www.addictionpat.org/) was used to help write this report.

\section{Inclusion criteria}

A tiered eligibility procedure was employed (see Figure 1). To be eligible to take part, participants had to reside in the UK, be aged $18+$ years, eng age in at least one unhealthy behaviour (i.e. cigarette smoking, daily or almost daily alcohol consumption, lack of daily physical activity of at least 30 minutes, or eating less than five portions of fruit or veg etables daily) and have no immediate plans to change their behaviour.

Sample recruitment 
A link to the study was sent to UCL students via the monthly myUCL e-newsletter and the study was advertised on four websites which allow researchers to connect with potential participants. In addition, a pay-per-click advert was posted on Facebook and a link to the study website was shared by members of the research team on social media platforms, including Twitter. Due to the recruitment strategies used, it was not possible to determine how many people were reached by the recruitment methods and to estimate a response rate.

\section{Procedure}

A website was built (www.healthcaretest.org) that enabled participants to take part in the research using either a computer or a mobile device. First, information about the research was provided and participants were asked to provide informed consent. Consenting participants $(n=843)$ were presented with an online survey to determine eligibility. Those who indicated that they engaged in at least one unhealthy behaviour $(n=$ 602) were assigned a target for change (i.e. fruit and vegetable consumption = 293, physical activity $=181$, alcohol consumption $=64$, cigarette smoking $=64$ ). Participants who engaged in more than one unhealthy behaviour were randomly assigned by a computer algorithm to a single target behaviour. Next, participants were asked about plans to change their behaviour. Those with no immediate plans to change $(n=177)$ were presented the RAL (see Table 1) and asked to select one statement that most closely described what they believed would need to change in order to change their target behaviour. Participants who completed the RAL were subsequently individually randomised using computer-generated random numbers on a 50-50 basis to one of the two intervention conditions.

Following intervention delivery, participants were thanked for taking part and were shown a web-link that they could visit for more information about changing their target behaviour. Participants who provided contact details were entered into a prize draw to win one of four $£ 50$ vouchers. Data were collected between May and December 2015. The study was approved by the University College London Research Ethics Committee (Project ID: 6692/001).

\section{Intervention}

Participants allocated to the on-target messaging condition received a targeted 
message which reflected their individual response to the RAL. Thirty-six brief messages were developed on the basis of the COM-B model and through discussion among the authors, with each message corresponding to one of the four target behaviours and to a different item on the RAL (see Table 1). The messages were typically 100 words long (see Appendix 1).

\section{Control}

Participants allocated to the off-target messaging received a randomly selected message from the bank of the 36 brief messages described above that was incongruent with their RAL response.

Table 1. The Risk Acceptance Ladder.

\begin{tabular}{|c|c|}
\hline $\begin{array}{l}\text { I would... } \\
\text { quit smoking } \\
\text { cut down on the amount that I drink } \\
\text { increase the amount that I am active } \\
\text { increase the amount of fruit and vegetables that I consume } \\
\text { but... }\end{array}$ & COM-B category \\
\hline a) I have not heard that XXXX was harmful or risky & Capability-psychological \\
\hline b) I have heard that XXXX is risky but never fully understood what the problem is & Capability - psychological \\
\hline c) I understand what people are saying about the risks of $X X X X$, but I don't believe it & Motivation - reflective \\
\hline d) I accept that XXXX is risky but don't care enough to do anything about it & Motivation - automatic \\
\hline e) I think it is worth $X X X X$, but it is not a priority at the moment & Motivation - reflective \\
\hline f) I don't think I can XXXX because things in my social world make it too difficult & Opportunity - social \\
\hline g) I don't think I can XXXX because things going on in my life make it too difficult & Opportunity - physical \\
\hline h) I don't think I can XXXX because I don't have the self-control & Motivation - automatic \\
\hline i) I want to XXXX, but I don't know how best to do it & Capability - psychological \\
\hline j) Other (none of the above) - Please specify... & - \\
\hline
\end{tabular}

\section{Measures}

\section{Covariates}

Data on gender (i.e. male, female, other), age in years and ethnicity (i.e. White, non-White [black, Asian, mixed, other]) were collected at the start of the survey. 


\section{Health behaviours}

Single-item measures were used to assess cigarette smoking status ("Do you smoke cigarettes at all nowadays?"), excessive alcohol consumption ("Do you drink alcohol every day or almost every day?"), insufficient physical activity ("Do you make sure that you walk or do other moderate physical activity for at least 30 minutes every day?") and low fruit and vegetable consumption ("Do you make sure that you eat at least five portions of fruit and vegetables each day?"). These were all coded as yes/no. A single item was used to assess behaviour change plans ("Which best describes your relationship with [target behaviour]?"). The response options were: 1) I am seriously trying to (e.g. eat more fruit and vegetables), 2) I have made a definite plan to (e.g. eat more fruit and vegetables) soon and 3) I have no immediate plans to (e.g. eat more fruit and vegetables).

\section{Risk Acceptance Ladder}

The 10 RAL items related to different aspects of the COM-B model (Capability - four items, Opportunity - two items, Motivation - three items; see Table 1). Participants were encouraged to select one item from the RAL which most closely described what they believed would need to change in order to change their targ et behaviour, with an additional, non-specific 'Other' option for those who felt none of the nine RAL items were adequate. Those who selected 'Other' were given the opportunity to provide their own reason as a free-text response. The current version of the RAL was arrived at after a number of iterations specifically relating to smoking (Cattaruzza \& West, 2013; Gould et al., 2014, 2016).

\section{Outcomes}

\section{Performance}

The RAL's performance was determined by two metrics: the percentage of participants who were able to select an applicable RAL response option (i.e. those who did not select 'Other') and by a question which assessed reported ease of use of the RAL ("How easy was it to make just one choice?"). The response options were: 1) very easy, 2) quite easy, 3) not very easy and 4) not at all easy.

\section{Effectiveness}


A behavioural outcome was used to assess the RAL's effectiveness. Following intervention delivery, participants were provided with a link to a website with information about how to change their target behaviour. The links provided were for the NHS Smokefree website (http://www.nhs.uk/smokefree); the Down Your Drink website (http://www.downyourdrink.org.uk); and the NHS Choices websites for physical activity (http://www.nhs.uk/livewell/fitness/Pages/Fitnesshome.aspx) and healthy eating (http://www.nhs.uk/livewell/5aday/Pages/5ADAYhome.aspx), respectively. A record was made if a participant clicked on the link provided; the act of clicking was interpreted as engagement with the health promotion materials.

\section{Data analysis}

Data were analysed in SPSS v.21. Chi-squared and t-tests were performed to determine any baseline differences between groups. Descriptive analyses were conducted to summarise the performance indicators (i.e. the ability to self-classify and ease of use of the RAL). A logistic regression analysis, adjusted for gender, age and ethnicity, was used to estimate the association between group allocation and the effectiveness indicator (i.e. clicking on the link provided vs. not clicking on the link). Free-text responses were coded and summarised in line with standard thematic analysis (Braun \& Clarke, 2006).

\section{Bayes Factors}

Given the relatively small sample size and thus low level of power to detect anything other than large effects, classical inferential statistics is limited in the event of nonsignificant results as it is unable to distinguish between insensitive data and the null hypothesis being correct. For this reason, we planned to analyse the data using a Bayesian approach in the case of non-significant results. The calculation of a Bayes Factor (BF) establishes the relative likelihood of the null versus the experimental hypothesis. Values greater than 3 or smaller than 1/3 are typically regarded as providing substantial evidence for the alternative or null hypothesis, respectively, with intermediate values indicating that data are insensitive to distinguish between the two (Dienes, 2011). BFs were calculated using an online calculator (www.lifesci.sussex.ac.uk/home/Zoltan_Dienes/inference/Bayes.htm) with the alternative hypotheses conservatively represented in each case by a half-normal distribution, where the alternative hypothesis is represented by a population mean of zero and the standard deviation of the distribution specified as an expected, reasonable effect size. This means that plausible values have been effectively represented between zero and twice the effect 
size, with smaller values represented as being more likely. As no prior data existed on likely effect sizes, we calculated BFs for postulated small $(O R=1.68)$, medium $(O R=3.47)$ and large $(O R=6.71)$ effects $(C h e n$, Cohen, \& Chen, 2010).

\section{Results}

\section{Participant characteristics}

Of 913 people visiting the study website, 843 (92\%) consented to take part in the study. After removing data for people who did not meet the minimum age requirement $(n=12)$ and duplicate survey submissions $(n=15), 816$ participants were included in the initial analysis (see Figure 1).

The sample was largely White, female and (with an average age of 30 years) relatively young (see Table 2). Respondents had on average $1.2(S D=0.9$ ) targ ets for behaviour change. The most common target was low fruit and vegetable consumption; more than half of respondents reported consuming less than the recommended five portions per day. The least frequent target was cigarette smoking; approximately 1 in 7 respondents reported current smoking (see Table 2). 


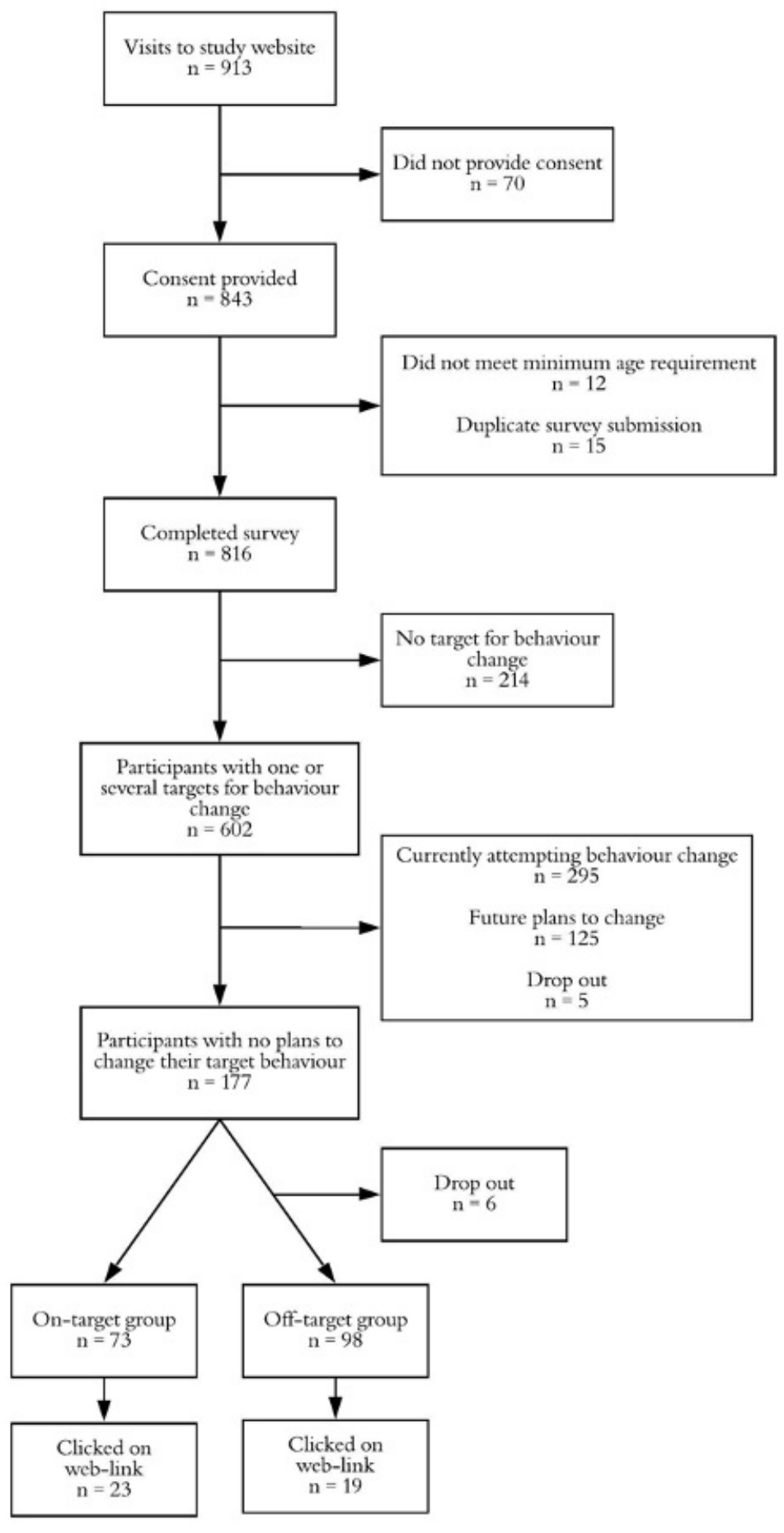

Figure 1. Procedural flow and participant allocation to the intervention conditions.

Table 2. Participant characteristics. 


\begin{tabular}{|c|c|c|c|c|}
\hline & $\begin{array}{l}\text { Full sample }(n= \\
\text { 816) }\end{array}$ & $\begin{array}{l}\text { Excluded from pilot } \\
\text { RCT }(n=639)\end{array}$ & $\begin{array}{l}\text { Included in pilot } \\
\text { RCT } \\
(n=177)\end{array}$ & $p$-value \\
\hline Gender, \% (n) & & & & $<0.001$ \\
\hline Male & $22.8(186)$ & $18.6(118)$ & $37.9(67)$ & \\
\hline Female & $76.7(626)$ & $80.8(512)$ & $61.2(110)$ & \\
\hline Other & $0.5(4)$ & $0.6(4)$ & - & \\
\hline Age, mean $(S D)$ & $30.7(12.8)$ & $30.01(12.31)$ & $32.9(14.2)$ & 0.020 \\
\hline Ethnicity, \% (n) & & & & 0.228 \\
\hline White & $84.4(689)$ & $83.8(531)$ & $86.4(153)$ & \\
\hline Non-White & $15.6(127)$ & $16.2(103)$ & $13.6(24)$ & \\
\hline \multicolumn{5}{|l|}{ Health behavioursa, \% (n) } \\
\hline Cigarette smoking & $14.5(118)$ & $11.0(70)$ & $26.0(46)$ & $<0.001$ \\
\hline Excessive drinking & $13.6(111)$ & $10.1(64)$ & $26.0(46)$ & $<0.001$ \\
\hline Physical inactivity & $39.7(324)$ & $37.9(240)$ & $45.8(81)$ & 0.035 \\
\hline Low fruit and vegetable consumption & $52.1(425)$ & $46.5(295)$ & $71.2(126)$ & $<0.001$ \\
\hline
\end{tabular}

${ }^{a}$ More than one behaviour could be selected.

\section{Performance}

A total of 177 participants had no immediate plans to change their target behaviour. This group was older and more likely to be male than those with plans, but no other differences were observed (see Table 2). Other than the item 'I heard that [insert target behaviour] is risky but never fully understood what the problem was', all RAL items were endorsed at least once. The most commonly endorsed items were 'I think it is worth [changing target behaviour] but it is not a priority at the moment' (28.3\%) and 'Other' (31.1\%) (see Table 3). Motivation (captured by three RAL items; see Appendix 1) was the most frequently endorsed COM-B category (65.8\%).

\section{Ability to select appropriate RAL response option}

Over two thirds of participants $(68.9 \%, 95 \% \mathrm{Cl}=61.8 \%-75.3 \%)$ were able to select an appropriate RAL item that identified a key reason why they had not yet changed their target behaviour.

\section{Ease of use}

Almost two thirds $(64.9 \%, 95 \% \mathrm{Cl}=57.5 \% \%-71.7)$ of participants found the RAL to be 'very easy' or 'quite easy' to use (see Table 3), but a significantly greater proportion of those who selected 'Other' in response to the RAL stated that it was 'not at all easy' to select one RAL item (14.3\% vs. 3.3\%; $\chi 2(1)=14.3, p=0.003)$. Over half of those who selected 'Other' $(n=29)$ provided their own reason for not yet changing their target behaviour (see Table 3). The most common themes were that participants disputed that 
their current behaviour is problematic and that a physical illness or condition prevented behaviour change. These themes align with the COM-B categories of psychological and physical capability, respectively. The remaining themes also addressed issues captured by COM-B categories, such as motivation and opportunity, including enjoyment of the risky behaviour, monetary costs of changing the behaviour, and beliefs about health consequences, such as: "To give up (smoking), I feel, would put my body into shock, and would probably kill me".

Table 3. Distribution of RAL responses, ease of use and reasons for selecting the 'Other' response option.

\begin{tabular}{ll}
\hline & $\%(n)$ \\
\hline RAL response ( $\boldsymbol{n}=177)$ & $6.2(11)$ \\
A - Unaware of the risks & $0(0)$ \\
B - Don't fully understand the problem & $3.3(6)$ \\
C - Don't believe the risks & $9.6(17)$ \\
D - Don't care enough to change & $28.3(50)$ \\
E - Not a priority & $2.8(5)$ \\
F - Social environment & $8.5(15)$ \\
G - Physical environment & $7.3(13)$ \\
H - Self control & $2.8(5)$ \\
I- Unsure how & $31.1(55)$ \\
J - Other & \\
\hline Ease of use ( $\boldsymbol{n}=\mathbf{1 7 1 )}$ & $25.2(43)$ \\
Very easy & $39.8(68)$ \\
Quite easy & $28.7(42)$ \\
Not very easy & $6.4(11)$ \\
Not at all easy & \\
\hline Other reasons for not changing behaviour ( $\boldsymbol{n}=29)^{*}$ & $48.3(14)$ \\
Disputes that current behaviour is problematic or unhealthy & $24.1(7)$ \\
Physical illness or condition (dietary constraints) preventing behaviour change & $6.9(2)$ \\
Enjoyment of activity preventing behaviour change & $3.4(1)$ \\
Monetary costs preventing behaviour change & $3.4(1)$ \\
Social aspects of behaviour preventing change & $3.4(1)$ \\
Disbelief of advice preventing behaviour change & $3.4(1)$ \\
Belief that they are doing as much as possible & $3.4(1)$ \\
Does not get around to following guidelines & $3.4(1)$ \\
Belief that their body wouldn't cope with change & \\
\hline *Those who selected 'Other' were asked to provide further reasons in a free-text box.
\end{tabular}

*Those who selected 'Other' were asked to provide further reasons in a free-text box.

\section{Effectiveness}

Following completion of the RAL, participants were randomised to the on- or off-target intervention conditions $(n=171)$. Those who selected 'Other' received off-target messages (as no on-targ et messages were available), which resulted in a higher proportion of participants allocated to the off-target (control) condition. There were no significant differences in baseline characteristics between those randomised to the on- or off-target conditions (see Table 4). 
Nearly twice as many participants allocated to the on-target group $(31.5 \%, \mathrm{n}=23)$ clicked on the link for further information about health behaviour change compared with those allocated to the off-target group $(19.4 \%, n=19)$, suggestive of an effect in the expected direction $(\mathrm{OR}=1.91,95 \% \mathrm{Cl}=0.95-3.86 ; \mathrm{p}=0.071)$. The planned Bayesian analysis provided moderate for the hypothesis of there being a small $(B F=3.2)$ but not a medium $(B F=2.4)$ or large $(B F=1.7)$ effect of the on-target messages.

After adjusting for gender, age and ethnicity, those in the on-target group were significantly more likely to click on the link to find out more about how to change their risky health behaviour compared with those in the off-target group $(\mathrm{OR}=2.1,95 \% \mathrm{Cl}=$ 1.0-4.3; $p=0.048$ ). The exclusion of those who had selected 'Other' (who were automatically assigned to the off-target group) did not change the direction of the effect, but the difference did no longer reached statistical significance $(O R=2.4,95 \% \mathrm{Cl}=$ 1.0-5.8; $p=0.063$ ). Due to the low power to detect differences for this comparison, we confirmed results again using a Bayesian analysis. This indicated that our results provided moderate support for the hypothesis of there being a small $(B F=3.3)$ and medium $(B F=$ 3.1) but not a large $(B F=2.4)$ effect.

Table 4. Participant characteristics by group allocation $(n=171)$.

\begin{tabular}{llll}
\hline & On-target $(\boldsymbol{n}=\mathbf{7 3})$ & $\begin{array}{l}\text { Off-target } \\
(\boldsymbol{n}=98)\end{array}$ & $p$-value \\
\hline $\begin{array}{l}\text { Gender, \% }(\boldsymbol{n}) \\
\quad \text { Male }\end{array}$ & $38.35(28)$ & $36.76(36)$ & 0.477 \\
$\quad$ Female & $61.64(45)$ & $63.27(62)$ & \\
$\quad-$ & - & \\
$\quad$ Other & $31.56(13.20)$ & $34.17(15.13)$ & 0.240 \\
Age, mean (SD) & & & 0.452 \\
$\quad$ Ethnicity, \% (n) & $84.93(62)$ & $86.73(85)$ & \\
$\quad$ White & $15.07(11)$ & $13.27(13)$ & \\
$\quad$ Non-White & & & \\
Behavioural target, \% (n) & $17.81(13)$ & $18.37(18)$ & 0.324 \\
$\quad$ Cigarette smoking & $31.14(22)$ & $14.29(14)$ & 0.124 \\
$\quad$ Excessive drinking & $9.59(7)$ & $13.27(13)$ & 0.289 \\
$\quad$ Physical inactivity & $42.47(31)$ & $54.08(53)$ & 0.232 \\
$\quad$ Low fruit and vegetable consumption & &
\end{tabular}

\section{Discussion}

The RAL appeared to be relatively easy to complete by the participants, with most participants being able to select a single rung on the ladder. Tailoring messaging to the 
selected rung may have increased the likelihood that the participant would take an initial step towards chang ing their behaviour. This pilot study was not pre-registered, and the results should hence be considered exploratory.

As over two thirds of participants were able to successfully use the RAL to classify the source of their inability to change, and more than half of participants found the RAL easy to use, it would seem that this new measure has good usability. The scalability of the RAL and the targeted messaging is also promising; once targeted messages have been developed, they can be delivered to a large number of people at the click of a button. This requires few resources and minimal input from trained staff. Hence, the RAL might be useful for clinicians and policy makers who wish to assess reasons for health behaviour inertia and to prompt eng agement with health behaviour change interventions.

When asking participants who selected 'Other' on the RAL to provide their own reason for not changing, the most commonly provided response was that participants did not think that their current behaviour, or the level at which they were currently performing a particular behaviour, was unhealthy or problematic. This theme closely relates to existing items on the RAL (i.e. the first two items), and maps onto the construct of psychological capability in the COM-B model. Nearly half of the participants who selected 'Other' fell into this category. Rewording the existing two items to more closely reflect people's understanding of its content (e.g. by means of cognitive interviews) may therefore help people self-classify more easily on the RAL. However, some free-text responses were not easily captured by existing RAL items, most notably the inability to change behaviour due to a physical illness or condition (endorsed by a quarter of participants who selected 'Other'). This previously unaddressed theme relates to physical capability in the COM-B model and an additional item to capture this issue has the potential to add to the value of the RAL. Thus, further qualitative work is required to explore a wider range of RAL items. Moreover, further research using the RAL would benefit from allowing participants to rate the messages they received in terms of perceived personal relevance and interest. Following further development of the measure, our results indicate that the evaluation of the RAL-based targeted messaging in a fully powered RCT may be warranted.

Key limitations of the study include a small sample size, unknown sample representativeness and a limited outcome measure.

\section{Conclusion}


The RAL could be a useful tool for targeting messag ing around increasing self-protective behaviours. Further research is required to improve the RAL and extend its evaluation to clinically meaning ful outcomes and additional types of behaviour.

\section{Acknowledgements}

OP receives salary support from Cancer Research UK (C1417/A22962). OP and LS are members of SPECT RUM, a UK Prevention Research Partnership Consortium (MR/S037519/1). UKPRP is an initiative funded by the UK Research and Innovation Councils, the Department of Health and Social Care (England) and the UK devolved administrations, and leading health research charities.

\section{Conflicts of interest}

OP and CS report no conflicts of interest. RW has undertaken research and consultancy for and receives travel funds and hospitality from manufacturers of smoking cessation medications (Pfizer, GlaxoSmithKline and Johnson and Johnson). LS has received a research grant and honoraria for a talk and travel expenses from manufacturers of smoking cessation medications (Pfizer and Johnson \& Johnson).

\section{Data availability}

The anonymised data that support the findings of this study are available on request from the corresponding author, LS.

\section{References}

Blissmer, B., \& McAuley, E. (2002). Testing the requirements of stages of physical activity among adults: The comparative effectiveness of stage-matched, mismatched, standard care, and control interventions. Annals of Behavioral Medicine, 24(3), 181-189. https://doi.org/10.1207/S15324796ABM2403_03

Braun, V., \& Clarke, V. (2006). Using thematic analysis in psychology. Qualitative Research in Psychology, 3(May 2015), 77-101. https://doi.org/10.1191/1478088706qp063oa

Cattaruzza, M. S., \& West, R. (2013). Why do doctors and medical students smoke when they must know how harmful it is? European Journal of Public Health, 23(2), 188-189. 
https://doi.org/10.1093/eurpub/ckt001

Chen, H., Cohen, P., \& Chen, S. (2010). How big is a big odds ratio? Interpreting the magnitudes of odds ratios in epidemiological studies. Communications in Statistics: Simulation and Computation, 39(4), 860-864.

https://doi.org/10.1080/03610911003650383

Dienes, Z. (2011). Bayesian versus orthodox statistics: Which side are you on? Perspectives on Psychological Science, 6(3), 274-290.

https://doi.org/10.1177/1745691611406920

Forouzanfar, M. H., Afshin, A., Alexander, L. T., Biryukov, S., Brauer, M., Cercy, K., ... Zhu, J. (2016). Global, regional, and national comparative risk assessment of 79 behavioural, environmental and occupational, and metabolic risks or clusters of risks, 1990-2015: a systematic analysis for the Global Burden of Disease Study 2015. The Lancet, 388, 16591724. https://doi.org/10.1016/S0140-6736(16)31679-8

Gould, G. S., Watt, K., McEwen, A., Cadet-James, Y., \& Clough, A. R. (2014). Validation of risk assessment scales and predictors of intentions to quit smoking in Australian Aboriginal and Torres Strait Islander peoples: A cross-sectional survey protocol. BMJ Open, 4(6), 1-10. https://doi.org/10.1136/bmjopen-2014-004887

Gould, G. S., Watt, K., West, R., Cadet-James, Y., \& Clough, A. R. (2016). Can smoking initiation contexts predict how adult Aboriginal smokers assess their smoking risks? A cross-sectional study using the "Smoking Risk Assessment Target." BMJ Open, 6(7), 1-9. https://doi.org/10.1136/bmjopen-2015-010722

Hay, S. I., Abajobir, A. A., Abate, K. H., Abbafati, C., Abbas, K. M., Abd-Allah, F., ... Bryane, C. E. G. (2017). Global, regional, and national disability-adjusted life-years (DALYs) for 333 diseases and injuries and healthy life expectancy (HALE) for 195 countries and territories, 1990-2016: A systematic analysis for the Global Burden of Disease Study 2016. The Lancet, 390, 1260-1344. https://doi.org/10.1016/S0140-6736(17)32130-X

Michie, S., Atkins, L., \& West, R. (2014). The Behaviour Change Wheel: A Guide to Designing Interventions. Silverback Publishing.

Michie, S., van Stralen, M. M., \& West, R. (2011). The behaviour change wheel: A new 
method for characterising and designing behaviour change interventions.

Implementation Science, 6(1), 42. https://doi.org/10.1186/1748-5908-6-42

NHS Digital. (2019). Health Survey for England 2018 - Adults' health-related behaviours.

Retrieved from https://digital.nhs.uk/data-and-information/publications/statistical/healthsurvey-for-england/2018

Prochaska, J. O., \& DiClemente, C. C. (1982). Transtheoretical therapy: Toward a more integrative model of change. Psychotherapy, 19(3), 276-288.

https://doi.org/10.1037/h0088437

Prochaska, J. O., \& DiClemente, C. C. (1983). Stages and processes of self-change of smoking: T oward an integ rative model of change. Journal of Consulting and Clinical Psychology, 51(3), 390-395. https://doi.org/10.1037/0022-006X.51.3.390

Quinlan, K. B., \& McCaul, K. D. (2000). Matched and mismatched interventions with young adult smokers: Testing a stage theory. Health Psychology, 19(2), 165-171. https://doi.org/10.1037/0278-6133.19.2.165

Romain, A. J., Bortolon, C., Gourlan, M., Carayol, M., Decker, E., Lareyre, O., ... Bernard, P. (2018). Matched or nonmatched interventions based on the transtheoretical model to promote physical activity. A meta-analysis of randomized controlled trials. Journal of Sport and Health Science, 7(1), 50-57. https://doi.org/10.1016/j.jshs.2016.10.007

Van Sluijs, E. M. F., Van Poppel, M. N. M., \& Van Mechelen, W. (2004). Stage-based lifestyle interventions in primary care: Are they effective? American Journal of Preventive Medicine, 26(4), 330-343. https://doi.org/10.1016/j.amepre.2003.12.010

West, R. (2005). Time for a change: putting the Transtheoretical (Stages of Change) Model to rest. Addiction, 1036-1039. https://doi.org/10.1111/j.1360-0443.2005.01139.x World Health Organisation. (2018). Noncommunicable diseases country profiles 2018.

\section{Appendix 1}




\section{Home page}

Welcome text

We are a team of researchers from University College London studying reasons why people engage in activities that affect their health and how some people might be encouraged to adopt more healthy lifestyles.

We would be extremely grateful if you could help with this study by completing a short questionnaire. We think it should take no more than about 10 minutes of your time.

Thank you very much for your help.

\section{Explanation of study}

You will be asked a few questions including questions on smoking, alcohol consumption, physical activity, and fruit and vegetable consumption. Then you might also be provided with some information about one of these activities. The survey will last approximately 10 minutes.

You are free to choose whether or not to take part in this study and of course you can stop at any time.

To take part, you should be at least 18 years of age and a UK resident.

As a thank you for helping with our research we would like to offer you the option to enter into a prize draw to win one of four $£ 50$ prizes. You will only be entered into the prize draw if you complete the survey.

If you would like to be entered into the prize draw please enter your email address below

<space to enter email address>

All personal information, including your email address, will be held in strict confidence. After the prize draw, your email address will be deleted. The results of the study may be published for scientific purposes but publications will not contain any personal information that could identify you. This study has been approved by University College London's Committee on the Ethics of Non-NHS Human Research [UCL Ethics Project ID: 6692/001].

If you have any questions or would like additional information about the study, your rights as a participant, or wish to receive a summary of the overall results of the project please contact Claire Stevens - claire.stevens.14@ucl.ac.uk 


\section{Behavioural questionnaire (100w)}

Here is a short questionnaire including questions about your lifestyle.

Please make sure you answer all the questions.

\begin{tabular}{l|l}
\hline Q.1 Gender & $\frac{\square \text { Male }}{\square \text { Female }}$ \\
\hline Q.2 Age & Please enter your age in years \\
\hline Q.3 Ethnicity & $\begin{array}{l}\text { Please indicate your ethnicity } \\
\square \text { White - British//rish/Other White } \\
\square \text { Black - African/Caribbean/Other Black } \\
\square \text { Asian - Indian/Pakistani/Bangladeshi/Chinese/Other Asian } \\
\square \text { Mixed - White/Black White/Asian Other Mixed } \\
\square \text { Other (please specify): }\end{array}$ \\
\hline
\end{tabular}

\begin{tabular}{l|l}
\hline Q.4 Importance of health & How much does your health matter to you? \\
& $\square$ Very much \\
& $\square$ Quite a bit \\
& $\square$ Somewhat \\
& $\square$ A little \\
& Not at all
\end{tabular}

\begin{tabular}{|c|c|}
\hline Q.5 Smoking & $\begin{array}{l}\text { Do you smoke cigarettes at all nowadays? } \\
\square \text { Yes } \\
\square \text { No }\end{array}$ \\
\hline Q.6 Alcohol & $\begin{array}{l}\text { Do you drink alcohol every day or almost every day? } \\
\square \text { Yes } \\
\square \text { No }\end{array}$ \\
\hline Q.7 Physical activity & $\begin{array}{l}\text { Do you make sure that you walk or do other moderate physical } \\
\text { activity for at least } 30 \text { minutes every day? } \\
\square \text { Yes } \\
\square \text { No }\end{array}$ \\
\hline Q.8 Fruit and Vegetables & $\begin{array}{l}\text { Do you make sure that you eat at least } 5 \text { portions of fruit and } \\
\text { vegetables each day? } \\
\square \text { Yes } \\
\square \text { No }\end{array}$ \\
\hline
\end{tabular}


3.a. Focus on smoking - instructions (100w)

The rest of this survey will focus on smoking.

Please answer the question below.

Which best describes your relationship with smoking?

a) I am trying to quit smoking

b) I have made a definite plan to quit smoking soon

c) I have no immediate plans to quit smoking

\section{4.a What might it take?}

Now we would like you to think carefully about what it might take for you to stop smoking.

Please read through the statements below, and select the one statement that you think most closely applies to you.

I would stop smoking now but...

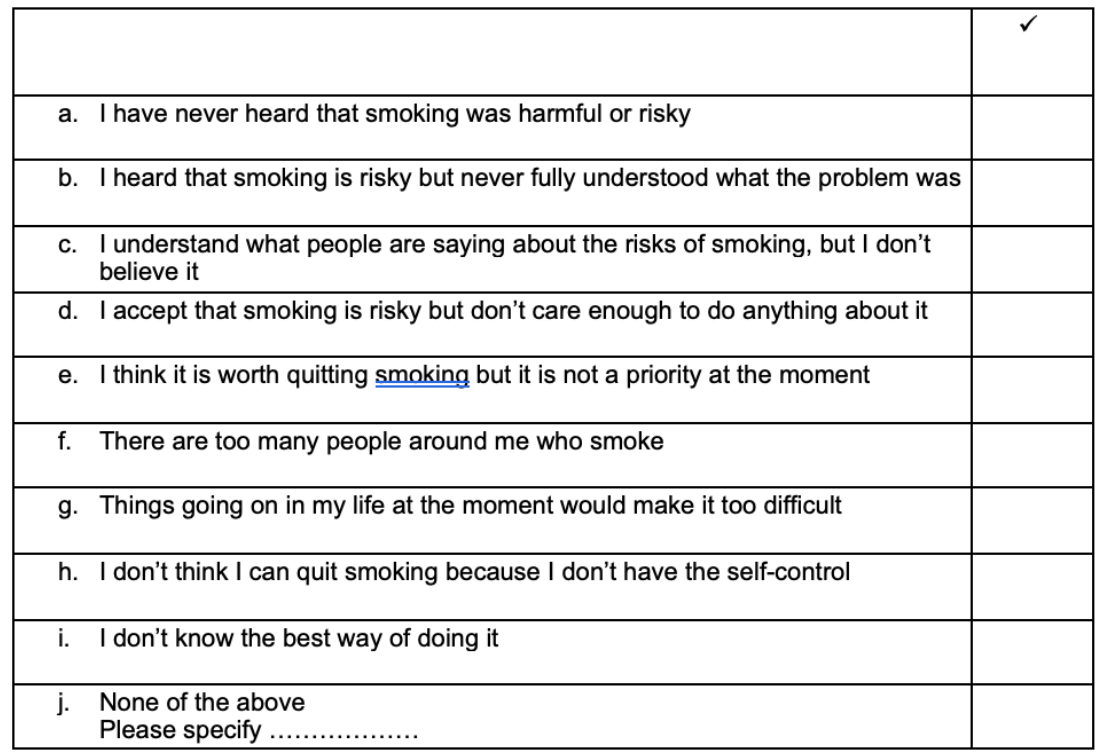


How easy was it to choose just one answer?

$\square$ Very easy

$\square$ Quite easy

$\square$ Not very easy

$\square$ Not at all easy

3.b. Focus on Alcohol - instructions (100w)

The rest of this survey will focus on alcohol.

Please answer the question below.

What best describes your relationship with alcohol?

a) I am trying to cut down on my drinking

b) I have made a definite plan to cut down on my drinking soon

c) I have no immediate plans to cut down on my drinking

4.b What might it take?

Now we would like you to think carefully about what it might take for you to cut down the amount you drink.

Please read through the statements below, and select the one statement that most closely applies to you.

I would cut down on the amount that I drink but...

\begin{tabular}{|c|c|}
\hline & $\checkmark$ \\
\hline a. I have not heard anything to suggest that the amount that I drink is harmful & \\
\hline $\begin{array}{l}\text { b. I have heard that the amount I drink is risky but I have not really understood } \\
\text { why }\end{array}$ & \\
\hline $\begin{array}{l}\text { c. I understand what people are saying about the risks of the amount I drink, but } \\
\text { I don't believe it }\end{array}$ & \\
\hline $\begin{array}{l}\text { d. I accept that drinking too much is risky but don't care enough to do anything } \\
\text { about it }\end{array}$ & \\
\hline $\begin{array}{l}\text { e. I think it is worth cutting down the amount I drink, but it is not a priority at the } \\
\text { moment }\end{array}$ & \\
\hline $\begin{array}{l}\text { f. I don't think I can cut down the amount I drink because things in my social } \\
\text { world make it too difficult }\end{array}$ & \\
\hline $\begin{array}{l}\text { g. I don't think I can cut down the amount I drink because things going on in my } \\
\text { life make it too difficult }\end{array}$ & \\
\hline
\end{tabular}




\begin{tabular}{|c|c|}
\hline h. & $\begin{array}{l}\text { I don't think I can cut down the amount I drink because I don't have the self- } \\
\text { control }\end{array}$ \\
\hline i. & I want to cut down the amount I drink, but I don't know the best way to do it \\
\hline & $\begin{array}{l}\text { None of the above } \\
\text { Please specify............... }\end{array}$ \\
\hline
\end{tabular}

How easy was it to choose just one answer?

$\square$ Very easy

$\square$ Quite easy

$\square$ Not very easy

$\square$ Not at all easy

3.c Focus on physical activity _ instructions (100w)

The rest of this survey will focus on physical activity.

Please answer the question below.

Which best describes your relationship with physical activity?

a) I am trying to become more physically active

b) I have made a definite plan to become more physically active soon

c) I have no immediate plans to become more physically active

\section{4.c What might it take?}

Now we would like you to think carefully about what it might take for you to become more physically active.

Please read through the statements below, and select the one statement that most closely applies to you.

I would increase the amount that I am active but...

\begin{tabular}{|l|l|}
\hline & $\checkmark$ \\
\hline a. I never heard that being inactive was harmful or risky & \\
\hline b. I heard that being inactive is risky but never fully understood what the problem \\
was
\end{tabular}




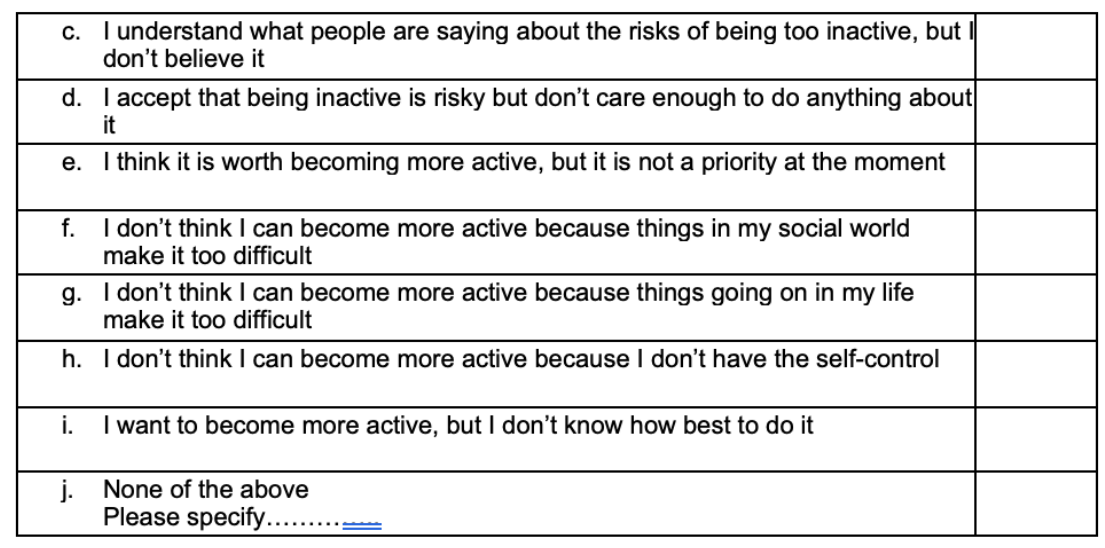

How easy was it to make your choice?

$\square$ Very easy

$\square$ Quite easy

$\square$ Not very easy

$\square$ Not at all easy 
3.d. Focus on fruit and veg - instructions (100w)

The rest of this survey will focus on diet.

Please answer the question below.

Which best describes your relationship with healthy eating?

a) I am seriously trying to eat more fruit and vegetables

b) I have made a definite plan to eat more fruit and vegetables soon

c) I have no immediate plans to eat more fruit and vegetables

4.a What might it take?

Now we would like you to think carefully about what it might take for you to eat more fruit and vegetables.

Please read through the statements below, and select the one statement that most closely applies to you.

I would eat more fruit and vegetables but...

\begin{tabular}{|c|c|}
\hline & $\checkmark$ \\
\hline $\begin{array}{l}\text { a. I have not heard that eating not enough fruits and vegetables was harmful or } \\
\text { risky }\end{array}$ & \\
\hline $\begin{array}{l}\text { b. I have heard that eating a poor diet is risky but never fully understood what } \\
\text { the problem is }\end{array}$ & \\
\hline $\begin{array}{l}\text { c. I understand what people are saying about the risks of eating a poor diet, but I } \\
\text { don't believe it }\end{array}$ & \\
\hline $\begin{array}{l}\text { d. I accept that eating a poor diet is risky but don't care enough to do anything } \\
\text { about it }\end{array}$ & \\
\hline e. I think it is worth eating more healthily, but it is not a priority at the moment & \\
\hline $\begin{array}{l}\text { f. I don't think I can eat more healthily because things in my social world make it } \\
\text { too difficult }\end{array}$ & \\
\hline $\begin{array}{l}\text { g. I don't think I can eat more healthily because things going on in my life make it } \\
\text { too difficult }\end{array}$ & \\
\hline h. I don't think I can eat more healthily because I don't have the self-control & \\
\hline i. I want to eat more healthily, but I don't know how best to do it & \\
\hline $\begin{array}{ll}\text { j. } & \text { None of the above } \\
& \text { Please specify....... }\end{array}$ & \\
\hline
\end{tabular}


How easy was it to make your choice?

$\square$ Very easy

$\square$ Quite easy

$\square$ Not very easy

$\square$ Not at all easy

\section{Something to help you on your way}

Thank you very much for answering those questions. Based on your answers we have selected some information that we think might interest you.

\begin{tabular}{|c|c|c|}
\hline \multirow[t]{4}{*}{ 1. Smoking } & A & $\begin{array}{l}\text { Not everyone knows quite how harmful smoking is. If they do not stop, } \\
\text { smokers die an average of } 10 \text { years earlier than non-smokers and } \\
\text { smokers suffer from diseases of old age much earlier than non- } \\
\text { smokers. There is no safe level of smoking. People who do not smoke } \\
\text { every day still suffer a huge increase in risk, particularly from heart } \\
\text { disease. } \\
\text { Stopping smoking at any age leads to a longer, happier, healthier life. }\end{array}$ \\
\hline & B & $\begin{array}{l}\text { It is not always easy to fully understand the risks from something like } \\
\text { smoking. Some people think that perhaps it is similar to eating butter } \\
\text { or too much salt. Unfortunately it is much worse than that. Being a } \\
\text { smoker carries about the same risk as being morbidly obese } \\
\text { (BMI>40). By the age of } 40 \text {, smokers typically look and feel about } 10 \\
\text { years older than their true age. } \\
\text { Stopping smoking in ones } 20 \text { s or } 30 \text { s can reverse this. }\end{array}$ \\
\hline & C & $\begin{array}{l}\text { Some people find it hard to believe that smoking cigarettes can have } \\
\text { such a huge effect on their health, especially if they only smoke a few } \\
\text { cigarettes a day. The thing to remember is that the concentrations of } \\
\text { cancer-causing chemicals in cigarette smoke are enormous - and } \\
\text { would never be allowed in any other product. Exposure to these } \\
\text { chemicals in the most sensitive and delicate part of the body, the } \\
\text { lungs, causes serious damage to the cells. } \\
\text { Stopping smoking completely is the only way to reverse this damage. }\end{array}$ \\
\hline & D & $\begin{array}{l}\text { It's easy to put the harm caused by smoking out of one's mind and not } \\
\text { feel overly worried about it. It is only when we get a health scare that }\end{array}$ \\
\hline
\end{tabular}


we really start to worry - but by then it could be too late. One of the worst diseases caused by smoking is called Chronic Obstructive Pulmonary Disease. The lungs stop working properly and smokers end up not able to breathe - imagine your whole life breathing through a tiny straw and you will have a sense of what it is like.

Stopping smoking can put your mind at rest that the chances of this happening to you are every low indeed.

E It's easy to put off the decision to stop smoking - there is always another day. There is a big problem with this. After having smoked for a while, every day smokers carry on costs an average of 6 hours of life! And every day of smoking avoided gains those 6 hours back.

So there is no time like the present - stopping smoking really is urgent.

F It can be hard to stop smoking when people around you smoke there are just too many temptations. But people do manage it every day and if one person in a group stops this can prompt others to stop.

Stopping is incredibly important, whatever the obstacles and there is lots of good advice available on how to cope with others smoking when one is trying to stop.

G It is easy to think that now is not the right time to stop because there is too much going on in one's life. In fact research has shown that smoking does not help with stress - it actually makes it worse, and that the chances of success at stopping are just as good whenever you try.

Stopping smoking actually helps with stress and there is lots of good advice available for how to deal with life's pressures without smoking.

H Many people think they do not have the self-control needed to stop smoking. But it does not have to be like that. There are lots of things one can do to make it so much easier than it used to be. And in fact, how confident you are in your ability to stop has very little bearing on whether you will succeed.

When smokers stop they feel a huge sense of achievement and there is no reason why you could not be one of them. The one thing that guarantees failure is not trying.

Stopping smoking can be daunting when one does not know the best way to do it, but there is lots of excellent advice available - based on literally hundreds of studies. The key thing is to make that first step and to follow the advice.

The first step is to resolve to do something - whether it's stopping today, deciding to stop soon or even just trying to cut down. One can jump in the deep end or just put a toe in the water! 


\begin{tabular}{|l|l|l|}
\hline J & $\begin{array}{l}\text { If you are ready to stop smoking now - this is a great time to give it a } \\
\text { go. }\end{array}$ \\
\hline
\end{tabular}

\begin{tabular}{|c|c|c|}
\hline \multirow[t]{6}{*}{ 2. Alcohol } & $\mathbf{A}$ & $\begin{array}{l}\text { Not everyone knows about how harmful it is to drink too much. There } \\
\text { guidelines say that men should drink no more than } 3 \text { 'units' per day } \\
\text { and women should drink no more than } 2 \text {. Even at these levels, } \\
\text { drinking increases the risk of cancer and heart disease. } \\
\text { Cutting down to below the recommended levels could be a life } \\
\text { saver. }\end{array}$ \\
\hline & B & $\begin{array}{l}\text { Understanding why it's important not to drink too much is a first step } \\
\text { to doing something to protect your health. Even at quite low levels, } \\
\text { alcohol increases the risk of breast cancer and other cancers by } \\
\text { damaging the DNA in your cells. It also increases blood pressure } \\
\text { and increases the risk of heart disease. A big problem is that there is } \\
\text { no way of knowing who is susceptible - it could be anyone. } \\
\text { It is so much safer to make sure that one stays below the } \\
\text { recommended alcohol limits. }\end{array}$ \\
\hline & C & $\begin{array}{l}\text { It may seem hard to believe that getting drunk once or twice a } \\
\text { month, or drinking more than the recommended amount, can be so } \\
\text { bad for your health. But the guidelines are based on decades of } \\
\text { careful research and they have been written to help you make an } \\
\text { informed choice about how much you drink. That is because, even } \\
\text { quite low levels of drinking increase the risk of cancer and heart } \\
\text { disease. } \\
\text { It is so much safer to make sure that one stays below the } \\
\text { recommended alcohol limits. }\end{array}$ \\
\hline & D & $\begin{array}{l}\text { It is easy to put the risks from drinking too much out of one's mind. } \\
\text { Cutting down is a long way down the priority list compared with } \\
\text { enjoying the effects of alcohol. The trouble is that things have a way } \\
\text { of catching up with us and we end up regretting our mistakes when it } \\
\text { is too late. } \\
\text { It is worth at least having a look at how one can enjoy life as much } \\
\text { or more while drinking less. }\end{array}$ \\
\hline & $E$ & $\begin{array}{l}\text { It is so easy to put off doing something about one's drinking till } \\
\text { another day. The damage from drinking builds up over time and the } \\
\text { sooner one can get it down to recommended level the lower the risk } \\
\text { of serious disease or something bad happening when intoxicated. } \\
\text { Today is always a good day to make a start at getting drinking down } \\
\text { to safe levels. }\end{array}$ \\
\hline & $F$ & $\begin{array}{l}\text { Sometimes it can be hard to cut down one's drinking when one has } \\
\text { an active social life. But there are many ways of doing it and having } \\
\text { a good time - or even a better time! In fact, studies have shown that } \\
\text { the other people we are with tend to drink less than we think they do } \\
\text { - so manv of our friends are alreadv keepina within the quidelines. }\end{array}$ \\
\hline
\end{tabular}




\begin{tabular}{|c|l|l|}
\hline & $\begin{array}{l}\text { It's worth having a look at the excellent advice available on how to } \\
\text { socialise without drinking too much. }\end{array}$ \\
\hline $\mathbf{G}$ & $\begin{array}{l}\text { Cutting down on one's drinking can be hard when there is a lot going } \\
\text { on in our lives and we use drinking to help us unwind or cope. The } \\
\text { problem is that of course the drinking doesn't solve problems, it just } \\
\text { helps us to forget them for a while and they have a habit of coming } \\
\text { back to bite us even harder. } \\
\text { It is worth having a look at all the excellent advice available on how } \\
\text { to cope with life's difficulties without drinking too much. }\end{array}$ \\
\hline $\mathbf{H}$ & $\begin{array}{l}\text { Many people think they don't have the self-control needed to cut } \\
\text { down on their drinking. But there is lots of good advice available to } \\
\text { make it so much easier. And we often have a lot more self-control } \\
\text { than we think we have. } \\
\text { It is worth having a look at all the excellent advice available on how } \\
\text { to cut down on drinking without it being a struggle. }\end{array}$ \\
\hline $\mathbf{I}$ & $\begin{array}{l}\text { Sometimes it's hard to know where to start in cutting down one's } \\
\text { drinking. But that doesn't matter. The important thing is that one can } \\
\text { start at any time and then start learning from what happens. And } \\
\text { decades of research has shown us the kinds of things that are likely } \\
\text { to help. } \\
\text { It is worth having a look at all the excellent advice available on how } \\
\text { to cut down on drinking without it being a struggle. }\end{array}$ \\
\hline $\mathbf{J}$ & $\begin{array}{l}\text { If you are ready to cut down on your drinking now - this is a great } \\
\text { time to make a start. }\end{array}$ \\
\hline
\end{tabular}

\begin{tabular}{|l|l|l|}
\hline $\begin{array}{l}\text { 3. Physical } \\
\text { Activity }\end{array}$ & A & $\begin{array}{l}\text { Not everyone knows quite how harmful leading an inactive life is. } \\
\text { Over 3million deaths each year worldwide can be attributed to } \\
\text { people not getting enough physical activity. The guidelines state that } \\
\text { people should aim for at least } 150 \text { minutes of moderate physical } \\
\text { activity per week. } \\
\text { By becoming more active you will reduce your risk of heart disease } \\
\text { by up to 35\% and your risk of type Il diabetes by up to 50\%. }\end{array}$ \\
\hline B & $\begin{array}{l}\text { It can be difficult to understand the beneficial effect that physical } \\
\text { activity has on your health. Physical activity improves the condition } \\
\text { of your heart and blood vessels which lowers your blood pressure. } \\
\text { Extensive research has shown that not getting enough physical } \\
\text { activity, or even sitting for too long, puts you at an increased risk of } \\
\text { serious conditions such as type II diabetes or heart disease. } \\
\text { Simply by meeting the recommended guidelines of 150 minutes of } \\
\text { physical activity per week, you can lower your risk of premature } \\
\text { death by up to } 30 \% .\end{array}$ \\
\hline
\end{tabular}




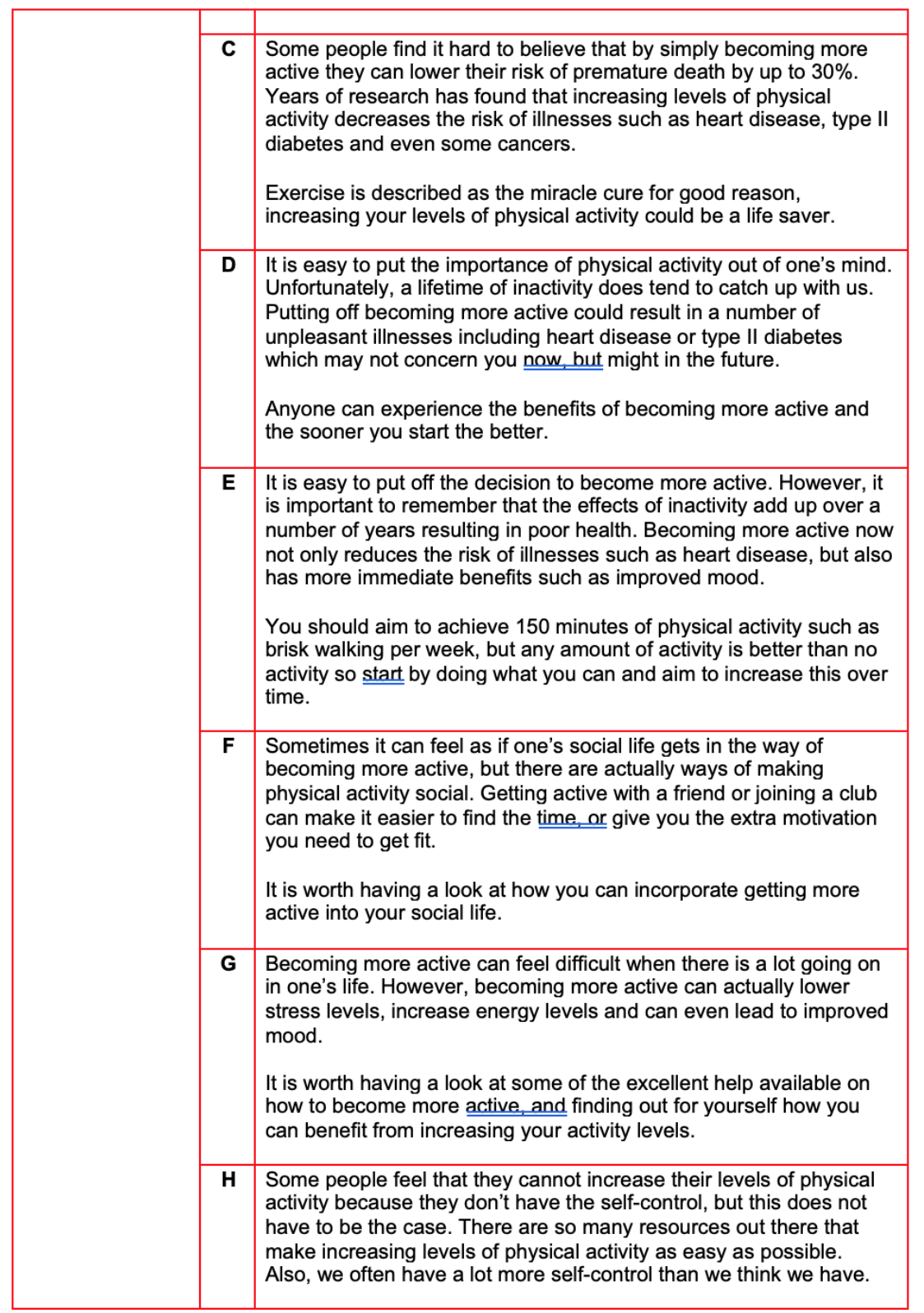




\begin{tabular}{|c|c|l|}
\hline & $\begin{array}{l}\text { It is worth looking at some of the excellent advice available to you } \\
\text { and giving it a go. }\end{array}$ \\
\cline { 2 - 3 } & I & $\begin{array}{l}\text { Sometimes it can be difficult to know where to start in increasing } \\
\text { one's physical activity levels. } \\
\text { Although guidelines advise 150 minutes of moderate physical } \\
\text { activity per week, any amount of activity is better than no activity. } \\
\text { Start off by doing what you can and aim to increase your activity } \\
\text { levels over time. } \\
\text { It is worth looking at some of the excellent advice available on } \\
\text { simple ways to increase your activity levels. }\end{array}$ \\
\hline J & $\begin{array}{l}\text { If you are ready to increase your levels of physical activity - this is a } \\
\text { great time to give it a go. }\end{array}$ \\
\hline
\end{tabular}




\begin{tabular}{|c|c|c|}
\hline \multirow[t]{6}{*}{ 4. Fruit and Veg } & $\mathbf{A}$ & $\begin{array}{l}\text { Not everyone knows how harmful eating too little fruit and veg can } \\
\text { be. The guidelines say that people should eat at least } 5 \text { portions of } \\
\text { fruit and veg every day. If everyone met this target } 42,000 \text { deaths } \\
\text { could be avoided in the UK each year. } \\
\text { Eating the recommended amount of fruit and veg will reduce your } \\
\text { risk of heart disease, stroke and even some cancers. }\end{array}$ \\
\hline & B & $\begin{array}{l}\text { It is not always easy to understand why eating a diet high in fruit and } \\
\text { veg is so beneficial to your health. Fruit and vegetables are high in } \\
\text { fibre- a diet high in fibre can reduce your risk of developing bowel } \\
\text { cancer. Fruit and vegetables also provide many of the essential } \\
\text { vitamins and minerals necessary for the body to function properly. } \\
\text { By increasing the amount of fruit and vegetables that you eat you } \\
\text { will reduce your risk of heart disease, stroke and even some } \\
\text { cancers. }\end{array}$ \\
\hline & C & $\begin{array}{l}\text { Some people find the benefits of eating a diet rich in fruit and } \\
\text { vegetables hard to believe. Rigorous scientific research has found } \\
\text { that eating a diet high in fruit and veg can help reduce your risk of } \\
\text { serious health conditions such as heart disease, stroke, and even } \\
\text { some cancers. It is also estimated that } 42,000 \text { deaths could be } \\
\text { avoided in the UK each year if people increased their fruit and veg } \\
\text { intake to the recommended } 5 \text { a day. } \\
\text { By making small changes to your diet, you could make huge } \\
\text { improvements to your health. }\end{array}$ \\
\hline & D & $\begin{array}{l}\text { It is easy to put the benefits of eating a diet high in fruit and veg to } \\
\text { the back of one's mind. However, it is important to remember that } \\
\text { over a number of years, eating a diet low in fruit and veg increases } \\
\text { one's chances of developing heart disease, stroke and even some } \\
\text { cancers. } \\
\text { It is so much better to eat more fruit and vegetables now than to } \\
\text { suffer the consequences in the future. }\end{array}$ \\
\hline & $\mathbf{E}$ & $\begin{array}{l}\text { It is easy to put off eating more fruit and veg. Sometimes the } \\
\text { consequences of eating too little fruit and veg may not seem obvious } \\
\text { or immediate, but unfortunately these things tend to catch up with } \\
\text { us. Over a number of years, eating a diet low in fruit and veg } \\
\text { increases one's chances of developing heart disease, stroke and } \\
\text { even some cancers. } \\
\text { Improving your diet now is one simple way to reduce your risk of } \\
\text { experiencing poor health in the future. }\end{array}$ \\
\hline & $\mathbf{F}$ & $\begin{array}{l}\text { Sometimes it can feel as if one's social life gets in the way of eating } \\
\text { more healthily. But an active social life does not have to mean a diet } \\
\text { low in fruit and veg. } \\
\text { It is important to think in advance about how you will get your } 5 \text { a } \\
\text { day. If you eat out a lot, try swapping unhealthier side dishes such }\end{array}$ \\
\hline
\end{tabular}




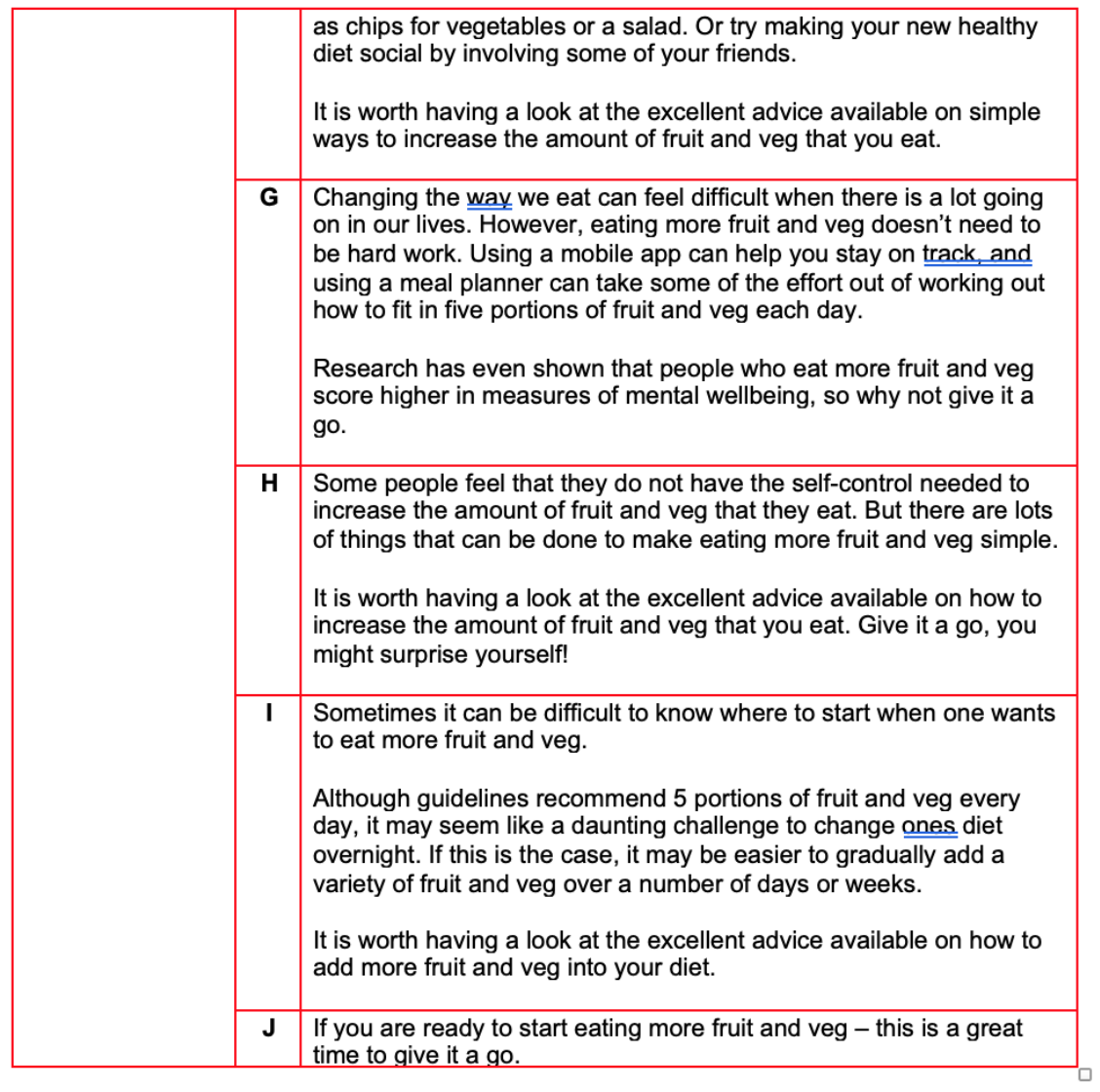

6. Interested in finding out more?

Thank you for using our website and answering our questions. We hope you found it interesting. We have done the research to find what we think is the best website right now for expert advice on how to (program chooses from stop smoking, cut down your drinking, get more exercise, eat more healthily depending on the focus).

Click on the link below and this will take you to that website. Otherwise you can simply close this page in your browser to finish the session. 


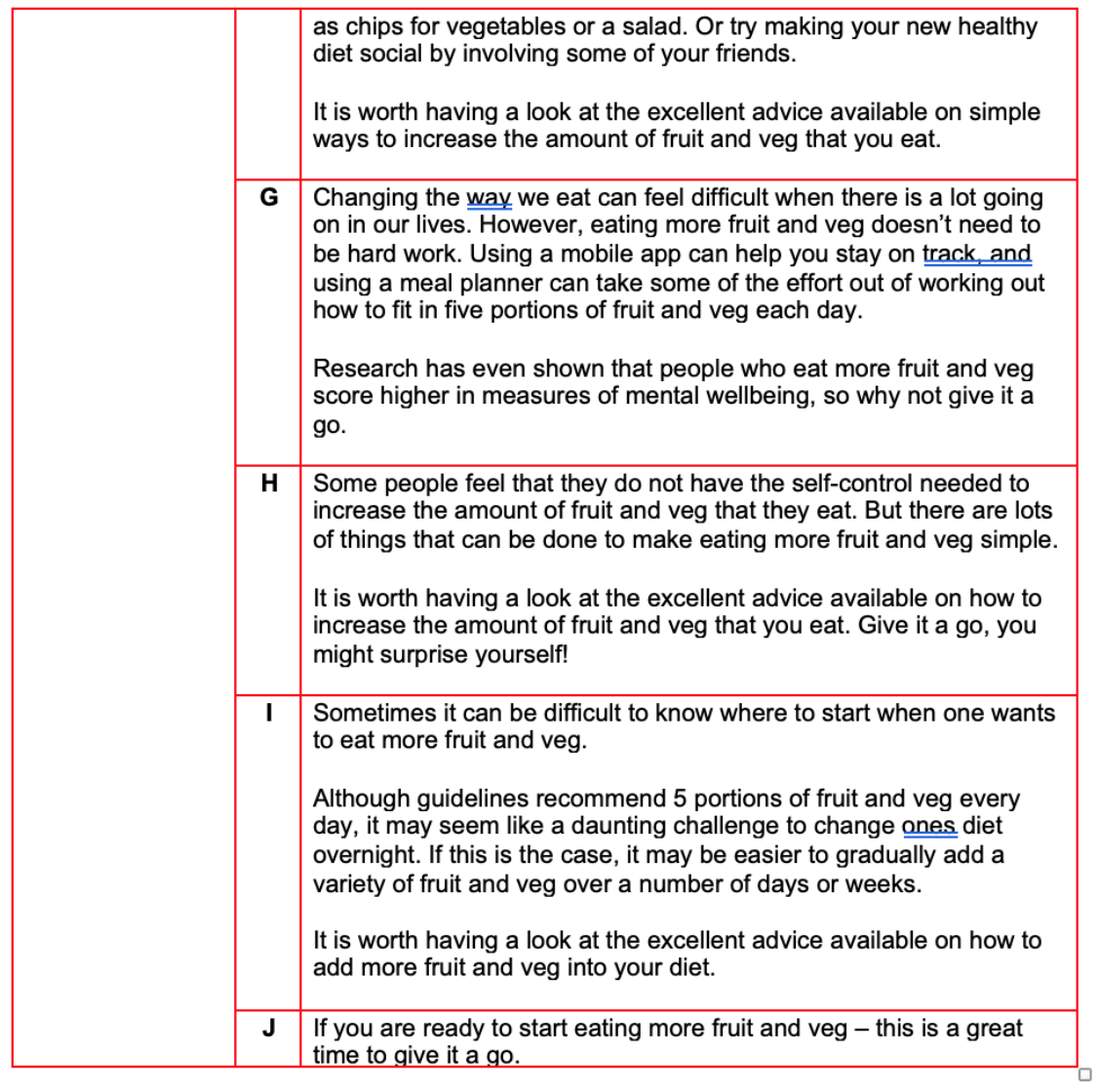

6. Interested in finding out more?

Thank you for using our website and answering our questions. We hope you found it interesting. We have done the research to find what we think is the best website right now for expert advice on how to (program chooses from stop smoking, cut down your drinking, get more exercise, eat more healthily depending on the focus).

Click on the link below and this will take you to that website. Otherwise you can simply close this page in your browser to finish the session. 
6.a Smoking

For expert advice on quitting smoking, click on the link below...

Websites:

\section{SMOKEFREE}

http://www.nhs.uk/smokefree

6.b Alcohol

For expert advice on how to cut down on your drinking click on the link below ...

We need to find a good website - probably Down Your Drink

http://www.downyourdrink.org.uk/

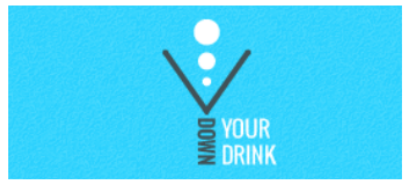

6.c Becoming more active

For expert advice on how to get more activity into your life click on the link below

http://www.nhs.uk/livewell/fitness/Pages/Fitnesshome.aspx

\section{WHS choices}

Your health, your choices

6d. Eating more healthily

For expert advice on how to eat more healthily click on the link below

http://www.nhs.uk/Livewell/5ADAY/Pages/5ADAYhome.aspx 


\section{Thank you}

This page comes up only if they have no behaviours that need to change

Thank you for taking part in this survey. It looks like you are already doing lots of the things that can help to keep you healthy.

Your responses have been recorded, and will help us to understand the importance of health to different people. 